\title{
Conventional and Advanced Glazing Technologies for Enhancing Thermal and Lighting Performance
}

\author{
Aya Walid Yehia AbdelHAdy El-Eshmawy ${ }^{1}$ \\ Ahmed Atef El Dessoqy Faggal ${ }^{1}$ \\ Abeer Mohamed Mustafa Eissa ${ }^{1}$ \\ ${ }^{1}$ Department of Architecture, Faculty of Engineering, Ain Shams University.
}

\begin{abstract}
Glass is one of the oldest man-made material that is widely used in architecture. As it is a translucent material, it permits a full penetration of direct sunlight but may also increase the internal space temperature and then increasing cooling loads and energy consumption. As the need for energy optimization is very important and glazing is considered a weak point in any building, the selection of glazing assumes tremendous significance. This paper reviews the different types of glazing which can be categorized into conventional and advanced to optimize the thermal and the lighting performance according to their properties and insulation values. Conventional glazing includes the clear glazing whether it is single double or triple, the tinted glazing, the reflective glazing, and the low-E glazing. Advanced glazing which is mainly the insulated glazing unit such as the gas filled glazing, the vacuum glazing, the aerogel glazing and the phase change material glazing.
\end{abstract}

\section{Keywords}

Conventional glazing, Advanced glazing, Insulated glazing units (IGU), Thermal performance, Lighting performance.

\section{Introduction}

Building consumes an enormous amount of energy worldwide to maintain indoor thermal performance. The energy consumption for the building's accounts for around $20 \%$ to $40 \%$ impacting at least $30 \%$ of the $\mathrm{CO} 2$ accounted to developed countries. Achieving thermal comfort has been a complicated issue especially in extreme climate conditions which increase the use of HVAC systems that by its turn increases the energy consumption of the building.(Pérez-Lombard et al., 2008)

Windows are directly related to thermal and lighting comfort as they are the main component in any building that permits the penetration of natural daylighting and heat transfer. Windows are also considered the weak point in any building as natural sunlight in any space may cause an increase in the internal temperatures and they may permit leakage. Almost $70 \%$ to $80 \%$ of the area of any window is made of glass so studying the effect of the glass used will have a great effect on the indoor environment.(Karlsson, 2001) 
Glazing is a translucent material that generates a pleasant and an aesthetically atmosphere in the space, it allows a view outward as well as inward connecting between the outdoor nature and the internal spatial atmosphere. Being a transparent material, glass permits a full penetration of direct sunlight that is necessary for the indoor environmental quality but may cause an increase in the internal space temperature. Visual transmittance of the glazing unit is important as it determines the amount of daylight through the glazing unit. So, the desired criteria of a glazing system from energy savings point of view are that it should possess higher transmittance in visible spectrum and lower transmittance in infrared region. (Ghoshal \& Neogi, 2014).

Glazing can be divided into conventional and advanced glazing. Conventional glazing includes the simple glazing like the clear glazing which can be a single , double, or triple glazing. Some coatings may be added to enhance its insulation properties such as the low-E coating and the reflective coatings. Tinted glazing is also one of the mostly used glazing. All types of tints and coatings can be added to a double and a triple glazing to ameliorate the properties of the fenestration.

The next evolution of the glazing is the use of the insulated glazing units where multiple layers of glass are used and some materials are inserted between these layers to adjust the overall properties of the window. The gap between the glass panes may be filled with inert gas that has a low thermal conductivity or by new materials that have good insulation properties while permitting the visual transmittance of the sunlight into the space.

\section{$>$ Research Problems}

Rapid increase in energy consumption in building sector is because of heating, cooling, and lighting loads. As windows is the main element responsible for the daylighting penetration that can increase indoor temperature or cause inadequate lighting level, glazing in any window must be chosen carefully. Non-appropriate glazing type can increase cooling loads in hot climate or lighting loads if it does not meet the required lighting level.

\section{$>$ Research Objectives}

This paper contributes to improving thermal and lighting conditions in any space through the type of glazing used by studying the properties of each type that affect the insulation properties of the glazing such as the U-value, the solar heat gain coefficient and the properties that affect the lighting performance into the space like the visible light transmittance. By studying these parameters and applying them in an architectural space, it can be concluded the best glazing types that ameliorate thermal and lighting performance. 


\section{$>$ Research Methodology}

This research discusses the conventional and advanced glazing types, their concept, insulation values and configurations. It then investigates the thermal and the lighting effect of these glazing types in an office through a simulation to compare between.

\section{Glazing Performance factors}

The important role of a glazing is to provide ventilation, daylighting, solar heat gain and aesthetics. There are three main key parameters that determine the thermal and the optical properties of any glazing which are the U-value, the solar heat gain coefficient, and the visible light transmission.

\subsection{U-value}

The U-value is used to express the insulation value of the window. It is the rate of heat loss of a fenestration, therefore, it represents the heat flow per hour for each square meter of fenestration product for $1^{\circ} \mathrm{K}$ difference between the indoor and the outdoor air temperature. It is evaluated on the air to air heat transfer through the window components (glass, frame, spacers and the space between the glass panes if the last 2 components exist). U-value is a number between 0 and 1 measured in $\mathrm{W} / \mathrm{m}^{2}{ }^{\circ} \mathrm{k}$ or Btu/hr-sq. $\mathrm{ft}-{ }^{\circ} \mathrm{F}$. The lower the U-value, the greater the fenestration's resistance to the heat flow and the better is the insulation. (Aguilar-Santana et al., 2019)

\subsection{Solar Heat Gain Coefficient (SHGC)}

The solar heat gain coefficient is the fraction of incident solar radiation admitted through a window. It is the ratio between the solar heat gain through the fenestration and the total incident solar radiation. It measures how well the fenestration blocks heat from the incoming solar radiation. It is a unitless value expressed as number between 0 and 1. The lower fenestration's SHGC, the less solar heat is transmitted.(Lawrence Berkeley Nation Laboratory, 2017)

\subsection{Visible Light Transmission}

Visible light transmittance of a glazing determines its visual performance, it is the percentage of the visible portion of the solar spectrum that is transmitted through a glazing product. It is a value between 0 and 1 . The higher the VLT, the higher will be the penetration of the light which is preferable to maximize natural daylighting. Visible transmittance does not affect thermal loads in a building but it is an important factor to evaluate the total energy efficiency of a fenestration product. (Lawrence Berkeley Nation Laboratory, 2017) 


\section{Conventional Glazing}

\subsection{Clear glazing}

It is the most common glass used as it is cheaper than other types and has a visible light transmittance about $90 \%$. Increasing the glass pane thickness will ameliorate its insulating properties such as the U- value and the SHGC. Table 1 shows the different properties of a single clear glazing. (Rezaei et al., 2017)

Table1 : Clear glazing thickness and characteristics

\begin{tabular}{|c|c|c|c|}
\hline Thickness(mm) & U-value & SHGC & VT \\
\hline 2 & 5.8 & 0.89 & 0.91 \\
\hline 4 & 5.8 & 0.87 & 0.90 \\
\hline 6 & 5.7 & 0.82 & 0.88 \\
\hline 8 & 5.6 & 0.80 & 0.87 \\
\hline 10 & 5.6 & 0.77 & 0.87 \\
\hline 12 & 5.5 & 0.74 & 0.85 \\
\hline 19 & 5.3 & 0.66 & 0.81 \\
\hline
\end{tabular}

\subsection{Tinted glazing}

Tined glazing is a clear glass with some metal component added to help retaining the glass pane transparency from the inside while absorbing a portion of the solar heat without blocking natural daylight. Tinting changes the color of the fenestration product but this color is durable and does not change over time. The tint has no effect on the U-factor but it changes the value of the SHGC which can be a benefit in the summer. (Lawrence Berkeley Nation Laboratory, 2017)

Blue and green tints allow a good penetration of visible light and decrease heat transfer compared to other colors of tints. For bronze and gray tints, the reduction in the visible light transmittance is greater than in the solar heat gain coefficient, this can decrease the amount of glare but also reduce the amount of daylight penetrating the space. Table 2 show the U-value, SHGC and VLT of different tinted glazing thickness and colors . (Rezaei et al., 2017)

Table 2 : Tinted glazing thickness and characteristics

\begin{tabular}{|c|c|c|c|c|}
\hline Color & Thickness $(\mathrm{mm})$ & U-value & SHGC & VLT \\
\hline \multirow{3}{*}{ Bronze } & 4 & 5.8 & 0.68 & 0.60 \\
\cline { 2 - 5 } & 6 & 5.8 & 0.60 & 0.49 \\
\cline { 2 - 5 } & 8 & 5.7 & 0.53 & 0.40 \\
\cline { 2 - 5 } & 10 & 5.6 & 0.48 & 0.33 \\
\hline \multirow{4}{*}{ Green } & 4 & 5.8 & 0.63 & 0.79 \\
\cline { 2 - 5 } & 6 & 5.8 & 0.55 & 0.73 \\
\cline { 2 - 5 } & 8 & 5.7 & 0.50 & 0.68 \\
\cline { 2 - 5 } & 10 & 5.6 & 0.46 & 0.63 \\
\hline Grey & 4 & 5.8 & 0.66 & 0.55 \\
\hline
\end{tabular}




\begin{tabular}{|c|c|c|c|c|}
\hline \multirow{3}{*}{} & 6 & 5.8 & 0.57 & 0.43 \\
\cline { 2 - 5 } & 8 & 5.7 & 0.50 & 0.34 \\
\cline { 2 - 5 } & 10 & 5.6 & 0.45 & 0.26 \\
\hline
\end{tabular}

\subsection{Reflective coating glazing}

Reflective glazing is used to increase the surface reflectivity of the glass pane which will reduce the SHGC but may also the reduce the VLT of the fenestration. It consists of a thin metallic layer which can have various metallic colors (bronzegold-silver). It can be applied on both clear and tinted glazing. When applied on tinted glass, the visible light transmittance decreases substantially more than the solar heat gain. The degree by which the SHGC is reduced depends on the glazing thickness, its reflectivity, and its location. It is better applied on the external surface of the glass facing the sunlight as it acts like a mirror. (Lawrence Berkeley Nation Laboratory, 2017)

\subsection{Low-Emissivity coating glazing (Low-E)}

Low Emissivity (low-E) coating is a thin, transparent metallic layer coating applied on glass such as tin, silver ow zinc to reduce the emissivity of the glass. Reducing the fenestration emittance will highly improve its insulating properties. Due to low-E coating, the improvement of insulating value is equivalent to adding another pane of glass in a multi-pane window. The first generation of low -E glazing is designed to minimize summer heat gains but allow natural daylighting that permits visible light but will block all other portions of the solar spectrum such as the ultraviolet light, the near infrared and the long infrared wave. The second generation was designed to reflect the solar near infrared wave like a heat mirror to reduce the total solar heat gain coefficient while maintaining high levels of visible light transmittance. (Aguilar-Santana et al., 2019)

According to (Saint-Gobain, 2018) in a double fenestration product, the placement of the low-E coating does not have affect the U-value but significantly affect the SHGC. There are two main categories of low-E coating: solar control low-E and passive low-E. The solar control low-E blocks the solar radiation to reduce cooling loads while passive low-E transmits solar radiation.

In cold climate, the best placement of low-E is on the outside surface of the inner pane to maximize winter passive solar gain with a slight reduction in the ability to control summer heat gain. In hot climate, it is better to apply the low-E coating on the inner surface of the outer pane to reduce solar heat gain and maximize energy consumption. In a triple glazing, applying low-E coating helps improving the overall U-value of the fenestration.(Lawrence Berkeley Nation Laboratory, 2017) 


\section{Advanced Glazing}

Insulated glazing unit (IGU) is a fenestration that consists of a multiple pane of glass (double or triple glazing) in which the spaces between the glass are used to increase the thermal insulation without affecting enormously the lighting performance as in figure 1. (Rathi, 2012). IGU have so many benefits, it prevents direct contact with sunlight and with the use of air conditioning the temperature difference between inside and outside is very less. Due to convection, air circulates and acts as a barrier and prevent the heat transfer from outside to inside and the cooled air from inside to outside which results in energy saving. The type of glazing used in any IGU is not only a clear glass but can be a low-E or tinted glass its overall insulation.

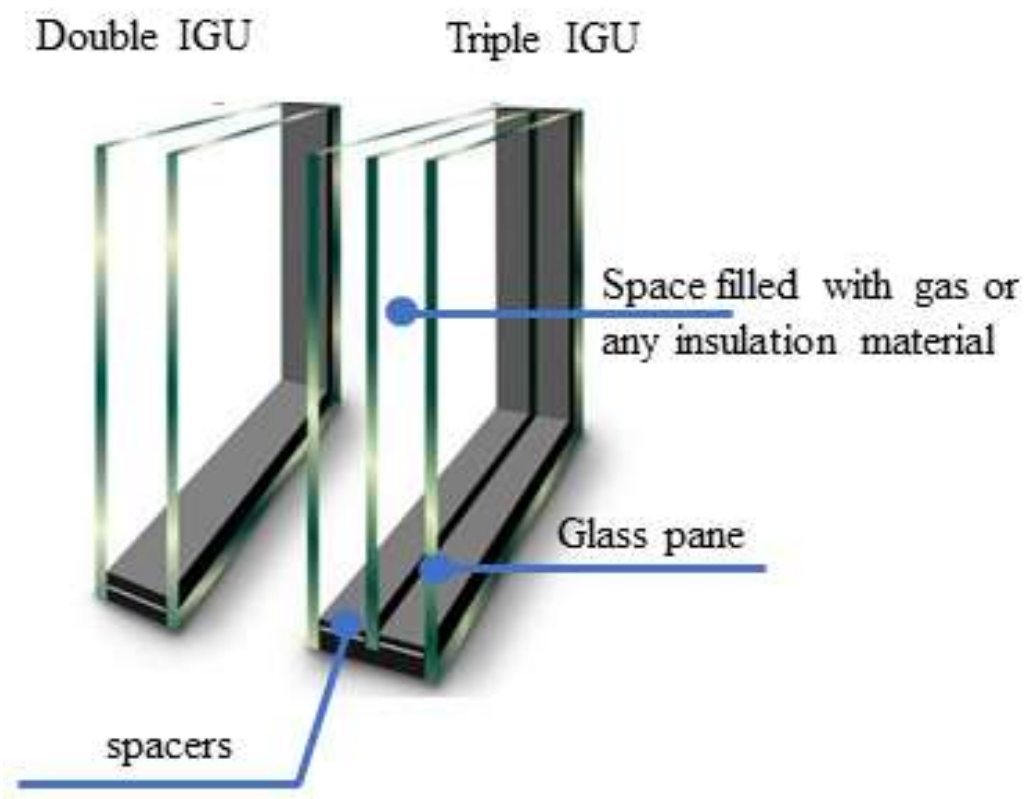

Figure 1 : Insulated Glazing Unit.

\subsection{Gas Filled Glazing}

Normally, the space in an insulated glazing unit is filled with air, but when filling this space with a less conductive gas, this will minimize the overall heat transfer between the two glass layers. Filling the spaces between the glass panes with noble gases or inert gases such as Argon, Krypton or Xenon will highly enhance its thermal performane. These gases are denser than air and have a low thermal conductivity hence reducing the amount of heat transfer through the IGU and the overall U-value of the fenestration. (Bizoňová \& Bagoňa, 2019)

When choosing between all inert or noble gases, the best option can be the Argon gas, it is most commonly used as it is the third most abundant gas in the world. As all inert gases, it is non-toxic, non-reactive, clear, odourless and what makes him mostly used that it is inexpensive. It is a cost effective option for gas filles fenestrations. Previous experiments have proven that argon filled windows reduce the window conductivity when comapred to air based mixtures (Aguilar-Santana et al., 2019). According to Aruteb \& Griffith, (1991)The optimum spacing between 
the glass panes for argon is about $(16 \mathrm{~mm})$ and the optimum U-value at this spacing is $0.536 \mathrm{~W} / \mathrm{m}^{2} . \mathrm{K}$. The thermal conductivity is $1.684 \times 10^{-2} \mathrm{~W} / \mathrm{m} . \mathrm{K}$ while the air has $2.496 \times 10^{-2} \mathrm{~W} / \mathrm{m} . \mathrm{K}$.

Krypton is used in the gas filled panels as it is so much denser than air which means it have high insulation properties and it is energy efficient. It is a high end material with better energy savings. Krypton is better used in narrow profiles windows as it fuctions better in thin gas between glass. The best spacing between glass pane is ablout $5 / 16$ " or $3 / 8$ ", for this reason , krypton is better used in a triple glazing where there is an extra layer of glass and an additional layer of insulation. The thermal conductivity of the Krypton gas is $9.43 \times 10^{-3} \mathrm{~W} / \mathrm{m} . \mathrm{K}$ and U-value at optimum gas space width is $0.397 \mathrm{~W} / \mathrm{m}^{2} . \mathrm{K}$. Aruteb \& Griffith,(1991) stated that the optimim spacing between glass panes in case of krypton in 1/2" like air.

One of the newest and the most specialist gas filled fenestration is the xenon, this gas is quite " cutting edge with energy performance". This gas makes the best option for large scale buildings such as commercial buildings as it is much heavier than the argon and the krypton and four and half times heavier than the air so it is very hard to leak. The xenon filled window is much more expensive than the other two gases with slightly better energy savings. The optimum gap between panes with xenon is $8 \mathrm{~mm}$, the thermal conductivity of the xenon gas is $0.005 \mathrm{~W} / \mathrm{m} . \mathrm{K}$ and it has reached the lowest $\mathrm{U}$-value among all gases $\left(0.28 \mathrm{~W} / \mathrm{m}^{2} . \mathrm{K}\right)$.

\subsection{Vacuum Glazing}

The use of vacuum glazing is a very promising solution to reduce heat transfer within the evacuated gap. The air in the gap between the glass panes is extracted out to form a vacuum space. It consists of two glass panes having a thickness around $3-4 \mathrm{~mm}$ separated of a vacuumed narrow space around $0.1-0.2 \mathrm{~mm}$. The inner surface of one or both glass panes is coated with a low-E to avoid radiative heat transfer. Conduction and convection are negligible because of the reduction in the number of gas particles that are responsible for heat transfer. (Ali et al., 2017)

Glazing units with such a low internal cavity may get damaged by stress exerted on it by atmospheric pressure . According to Ghoshal \& Neogi, (2014) this problem can be prevented by applying tiny supports pillars arranged in a squared grid. To maintain the vacuum in the internal space of the evacuated space, edge sealing is done as shown in figure 2. According to Gaoxun (2012) there is a relation between the diameter and length of pillar, for a $4 \mathrm{~mm}$ glass with pillars of $25 \mathrm{~mm}$ diameter and $0.125 \mathrm{~mm}$ height, it has a $\mathrm{U}$-value of $0.4 \mathrm{~W} / \mathrm{m}^{2} . \mathrm{K}$. For a $3 \mathrm{~mm}$ glass with pillars of $20 \mathrm{~mm}$ diameter and $0.25 \mathrm{~mm}$ height, the $\mathrm{U}$-value will be 1.2 $\mathrm{W} / \mathrm{m}^{2} . \mathrm{K}$. 


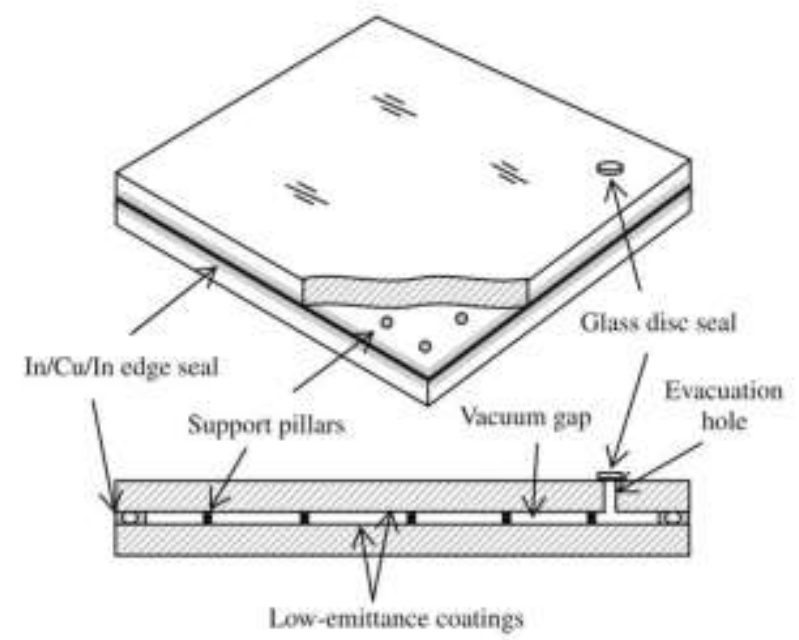

Figure 2 : Vacuum insulated glazing components. (source: (Ghoshal \& Neogi, 2014))

\subsection{Aerogel Glazing}

Aerogels also known as solid air is one of the most promising materials that can be used in a fenestration due to its light composition (density $1-150 \mathrm{~kg} / \mathrm{m}^{3}$ ) consisting of air and. They are dried gel with such a high porosity that they have lower thermal conductivity than air. It is a translucent insulating material which allows the penetration of natural daylighting and enhancing the thermal performance and the solar properties of the fenestration. Aerogels have thermal conductivity that varies between 0.01 to $0.02 \mathrm{~W} / \mathrm{m} . \mathrm{k}$ due to their small pore sizes. (Berardi, 2015)

There are two types of aerogel: monolothic and granular. Monolothic silica areogels are better to be used in glazing products due to their high solar transmittance than granule ones. The main problem of monolothic aerogels is that it can cause cracks in the fenestration when produced in large areas, and the maximum area that can be used without cracking is $0.58 * 0.58 \mathrm{~m}$ with a maximum thickness of $15 \mathrm{~mm}$ (Dowson et al., 2011). Schultz \& Jensen (2008) reported that a prototyope of $1.2 \mathrm{~m}^{2}$ of monolothic glazing aerogel consisting of four glass panes of $0.55 * 0.55 \mathrm{~m} * 15 \mathrm{~mm}$ was studied and different values were measured. This prototype showed that the U-value in the center of the pane was $0.66 \mathrm{~W} / \mathrm{m}^{2} . \mathrm{K}$ and the overall U-value was $0.72 \mathrm{~W} / \mathrm{m}^{2} . \mathrm{K}$. The direct solar transmittance was $75-76 \%$ while the normal transmittane of the visible spectrum was $85-90 \%$.

Granular aerogel is a good alternative of the monolothic aerogel as it is cheaper, more robust and easier to produce in large scales and buildings. It cannot be considered like the transparent fenestrations because the granules block the view to the outside but provide lower U-values and enhance light scaterring so it can be used in spaces that external view is not a necessity(Dowson et al., 2011). The most common size of the translucent aerogel granules is between $1 \mathrm{~mm}$ to $4 \mathrm{~mm}$. A US company named Cabot corporation produces two types of granular aeogel : Enova with granules size $2-1200 \mathrm{um}$ and $\mathrm{U}$-value $0.012 \mathrm{~W} / \mathrm{m}^{2} . \mathrm{K}$ and Lumira with granules size $0.7-4 \mathrm{~mm}$ and U-value $0.018-0.023 \mathrm{~W} / \mathrm{m}^{2} . \mathrm{K}$. 


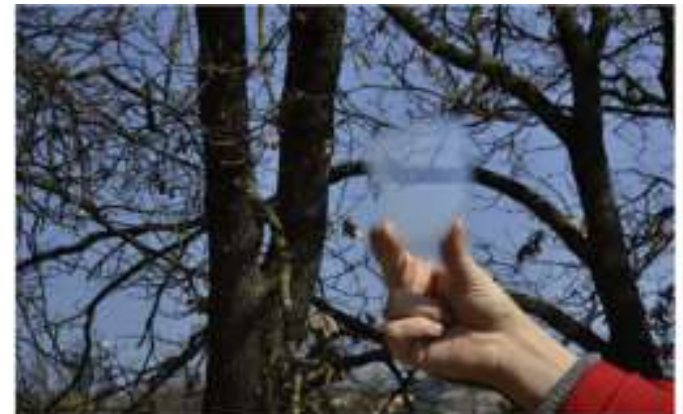

(a)

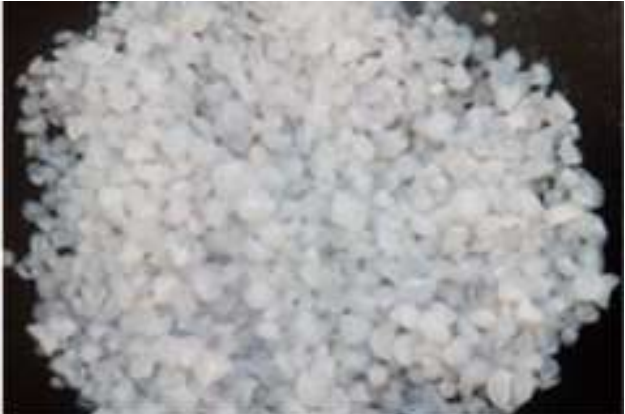

(b)

Figure 3 : a)monolothic aerogel b) granular aerogel

(Source : (Buratti \& Moretti, 2012))

\subsection{Phase change Material Glazing}

Phase change materials are substances that can absorb, store and release energy from surrounding materials due to latent heat concept and thermal energy storage. This material can change from solid state to liquid state when heated by absorbing energy in an endothermic process. When temperature decreases, the liquid state of the material will turn into solid state releasing all energy absorbed in an exothermic operation. (Aguilar-Santana et al., 2019)

The main aim of adopting the PCM into the glazing is to ameliorate the overall performance of the fenestration in terms of energy and comfort. The goal of this technique is to manage the direct solar heat gain which can cause overheating problems, decrease heat loss because of the PCM layer added while maintaining the penetration of the visible part of the solar radiation to be exploited for daylighting. Due to the PCM optical properties, the PCM layer absorbs and store most of the short wavelength infrared radiation, and the near infrared radiation and some of the visible radiation to let the other part of the visible radiation penetrates the space allowing daylighting. This basic technology can lead to both cooling and heating reductions, of betweem 1-9\% and 7-10\% respectively. (Vigna et al., 2018)

Goia(2017) stated that a PCM fenestration is composed of two glass panes each with $4 \mathrm{~mm}$ thickness and a $15 \mathrm{~mm}$ layer of commercial grade of paraffin wax. It is possible to observe between the solid state and the liquid state as in figure 4 as the PCM in the solid state is very translucent while it is similar to the conventional clear glazing in the liquid state. Glass X store is the most common PCM glazing used in fenestrations till now.

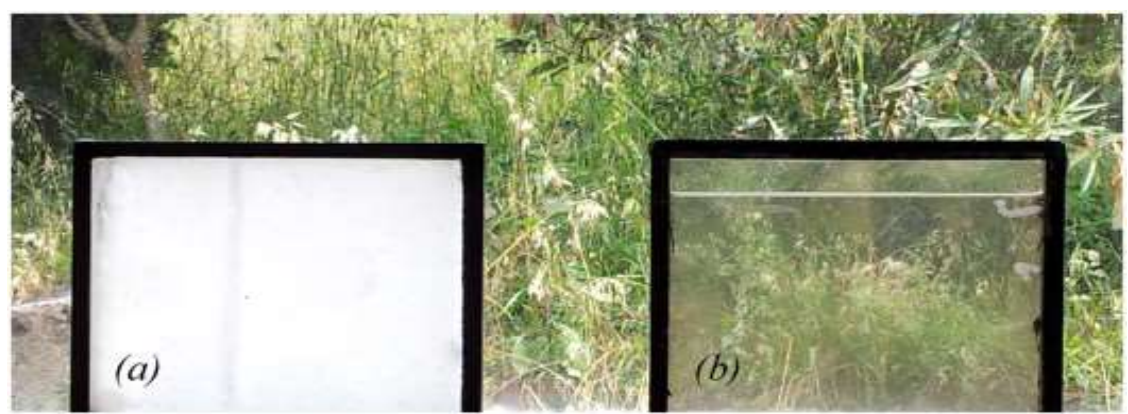

Figure 4 : PCM in solid state (a) and liquid state (b) (source : (Goia, 2017)) 


\section{Case Study and Results}

Previous glazing types were applied in a space in an office building to investigate the thermal and the lighting performance in the space. Design Builder software (version 6.1.0.006, 2000-2019 copyrights) for modelling and assigning activity template, construction template, and occupancy schedule. Moreover, Energy Plus (version 9.2.0) was used as an engine for thermal analysis and measurement of indoor thermal comfort. The weather file used in simulation was (EGY_Cairo.Intl.Airport.623660_ETMY.epw).

\subsection{Model Description}

The case study is a room in office building in an intermediate floor with dimension $5^{*} 5 \mathrm{~m}$ and $3.5 \mathrm{~m}$ finish to finish height. Its main window is in the southern elevation, with a WWR ration $50 \%$ as most of office buildings and the other three walls are solid. The construction materials consist of $25 \mathrm{~cm}$ solid brick wall, cement plaster and acrylic paint with $2 \mathrm{~cm}$ thickness from both side external and internal with a U-value 1.665 .

\subsection{Glazing types and Values}

The previous glazing types studied were investigated on the model. The values are obtained from the previous studies and from the companies producing the glazing types such as Saint Gobain company for the gas filled glazing, the Pilkington company for the vacuum glazing, Glass X for the PCM glazing and Lumira for the aerogel glazing. Tinted and reflective glazing are picked from Sphynx Glass company as an example.

Table 3 : Glazing types and Values.

\begin{tabular}{|c|c|c|c|}
\hline Glass type and description & U-value & SHGC & VLT \\
\hline Single clear 6mm & 5.778 & 0.819 & 0.811 \\
\hline Single tinted 6mm blue & 5.70 & 0.60 & 0.58 \\
\hline Single low-E coating 6mm & 3.447 & 0.65 & 0.84 \\
\hline Single reflective 6mm clear & 5.7 & 0.7 & 0.69 \\
\hline $\begin{array}{c}\text { Double clear glazing: 6mm clear glass-12 } \\
\text { mm air -6mm clear glass }\end{array}$ & 2.685 & 0.703 & 0.781 \\
\hline $\begin{array}{c}\text { Double Tinted glazing blue : 6mm tinted -16 } \\
\text { mm air- 6mm clear }\end{array}$ & 2.7 & 0.48 & 0.53 \\
\hline $\begin{array}{c}\text { Double reflective glazing: 6mm clear glass - } \\
\text { 16 mm air- 6mm clear glass }\end{array}$ & 2.7 & 0.6 & 0.62 \\
\hline $\begin{array}{c}\text { Double Low E glazing: 4mm low E glass - } \\
\text { 12mm air- 4mm clear glass }\end{array}$ & 1.790 & 0.591 & 0.761 \\
\hline $\begin{array}{c}\text { Double Argon Low E: 4mm low E glass- 16 } \\
\text { mm Argon- 4mm clear glass }\end{array}$ & 1.548 & 0.587 & 0.761 \\
\hline $\begin{array}{c}\text { Double Xenon Low E: 4mm low E glass - } \\
\text { 8mm Xenon - 4mm clear glass }\end{array}$ & 1.28 & 0.585 & 0.761 \\
\hline Double Vacuum glazing: 3mm glass-0.2 & 1.1 & 0.670 & 0.78 \\
\hline
\end{tabular}




\begin{tabular}{|c|c|c|c|}
\hline vacuum -3mm glass & 0.21 & 0.42 & 0.520 \\
\hline $\begin{array}{c}\text { Double Aerogel glazing: 6mm glass- 16 mm } \\
\text { granular aerogel- 6mm glass }\end{array}$ & 0.50 & 0.35 & 0.22 \\
\hline $\begin{array}{c}\text { Double PCM glazing: 4 mm glass-15mm } \\
\text { paraffin wax-4mm glass }\end{array}$ & 1.779 & 0.658 & 0.723 \\
\hline $\begin{array}{c}\text { Triple glazing: 4mm glass-12 mm air- 4mm } \\
\text { glass -12mm air -4mm glass }\end{array}$ & 1.017 & 0.466 & 0.651 \\
\hline $\begin{array}{c}\text { Triple low-E glazing: 4mm low E glass -12 } \\
\text { mm air- 4mm clear glass -12mm air -4mm } \\
\text { clear glass }\end{array}$ & 0.778 & 0.464 & 0.651 \\
\hline $\begin{array}{c}\text { Triple low-E Argon glazing: 4mm low E } \\
\text { glass-16 mm Argon- 4mm clear glass - } \\
16 \mathrm{~mm} \text { Argon -4mm clear glass }\end{array}$ & 0.69 & 0.46 & 0.651 \\
\hline $\begin{array}{c}\text { Triple low-E Krypton glazing: 4mm low E } \\
\text { glass -12 mm Krypton - 4mm clear glass - } \\
12 \mathrm{~mm} \text { Krypton -4mm clear glass }\end{array}$ & & 0.4 & 0.651 \\
\hline $\begin{array}{c}\text { Triple low-E Xenon glazing: 4mm low E } \\
\text { glass -8 mm Xenon- 4mm clear glass -8mm } \\
\text { Argon -4mm clear glass }\end{array}$ & 0.62 & & \\
\hline
\end{tabular}

\subsection{Thermal performance}

To measure the thermal performance of each glazing type, annual cooling loads are calculated in $\mathrm{KWH}$ and the results are illustrated in figure 5.

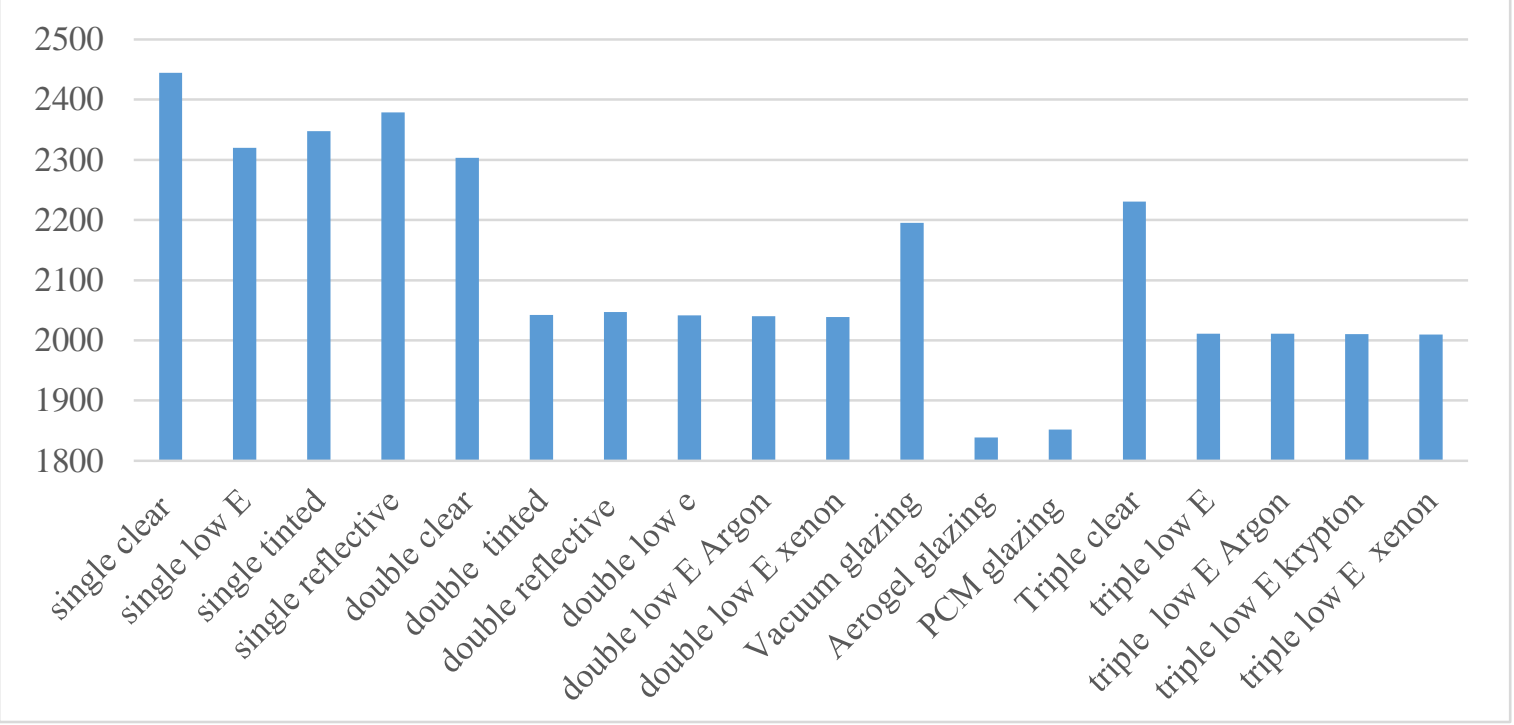

Figure 5 : Cooling loads in KWH by each glazing type 
It is noticed that from figure 5 that:

- The single glazing is the worst option while the aerogel glazing is the best option.

- Increasing the number of panes will increase the insulation properties of the fenestration and then the thermal performance.

- The single low-E glazing is the best alternative between all types of single glazing studied.

- The aerogel glazing is the best type among all double-glazing types followed by the PCM glazing and the vacuum glazing.

- The triple low-E Xenon is the most effective glazing between all triple glazing types but the difference between the xenon and the other gases is neglectable.

- When comparing between the single clear, double clear and triple clear, the single clear glazing is the worst among them followed by the double clear then the triple clear, but the difference between the double and triple is not very big.

\subsection{Lighting Performance}

To measure the lighting performance of each glazing type, the required lighting level was set as 400 lux as all office spaces as mentioned in IESNA lighting handbook. Annual lighting loads are calculated in $\mathrm{KWH}$ and the results are illustrated in figure 6 .

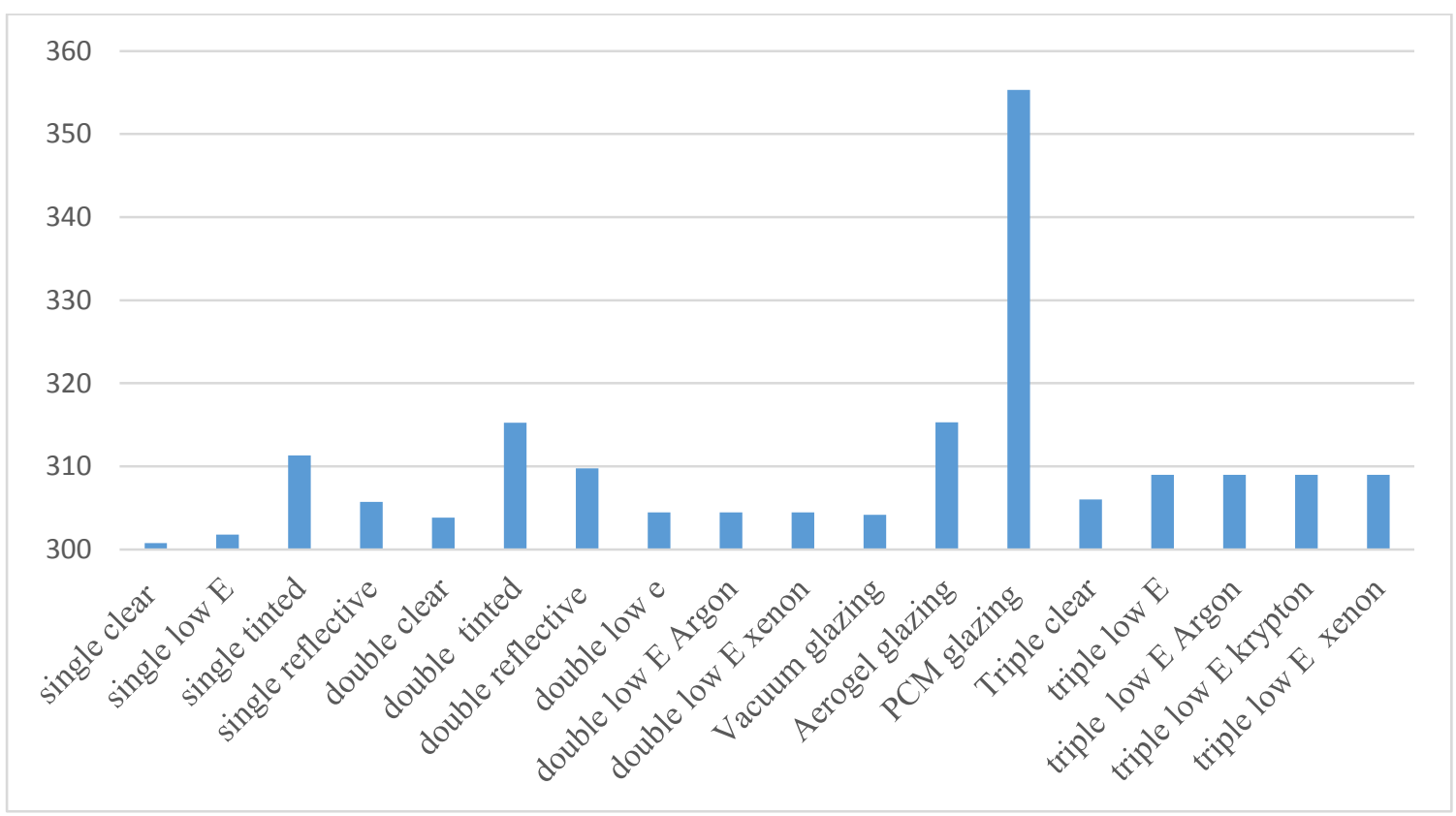

Figure 6 : Lighting loads in KWH by each glazing type 
It is noticed that from figure 6 that :

- The single clear glazing is the best type while the PCM glazing is considered the worst option.

- The clear glazing whether it is single, double, or triple can be the best option in terms of lighting.

- Between all single glazing types studied, the single clear is the best type followed by the single low-E.

- The double clear glazing is the best type between all double glazing studied followed by the vacuum glazing and the gas filled glazing.

- The triple clear is considered the best among triple glazing types studied, but the difference between the triple clear glazing and the triple low-E filled with gases is not huge.

- The tinted and the reflective glazing may increase lighting loads as they have a small VLT value, but they may not cause any glare like the clear glazing so they can be a better option than the clear one.

\section{Discussion and Conclusion}

The findings of this study showed that the insulated glazing units with all its forms show a better performance than the conventional glazing types. They have a good thermal performance due to their low U-value and most of them have a good VLT allowing natural daylighting and decreasing lighting loads. Figure 7 shows the total energy consumed by thermal and lighting loads of each type.

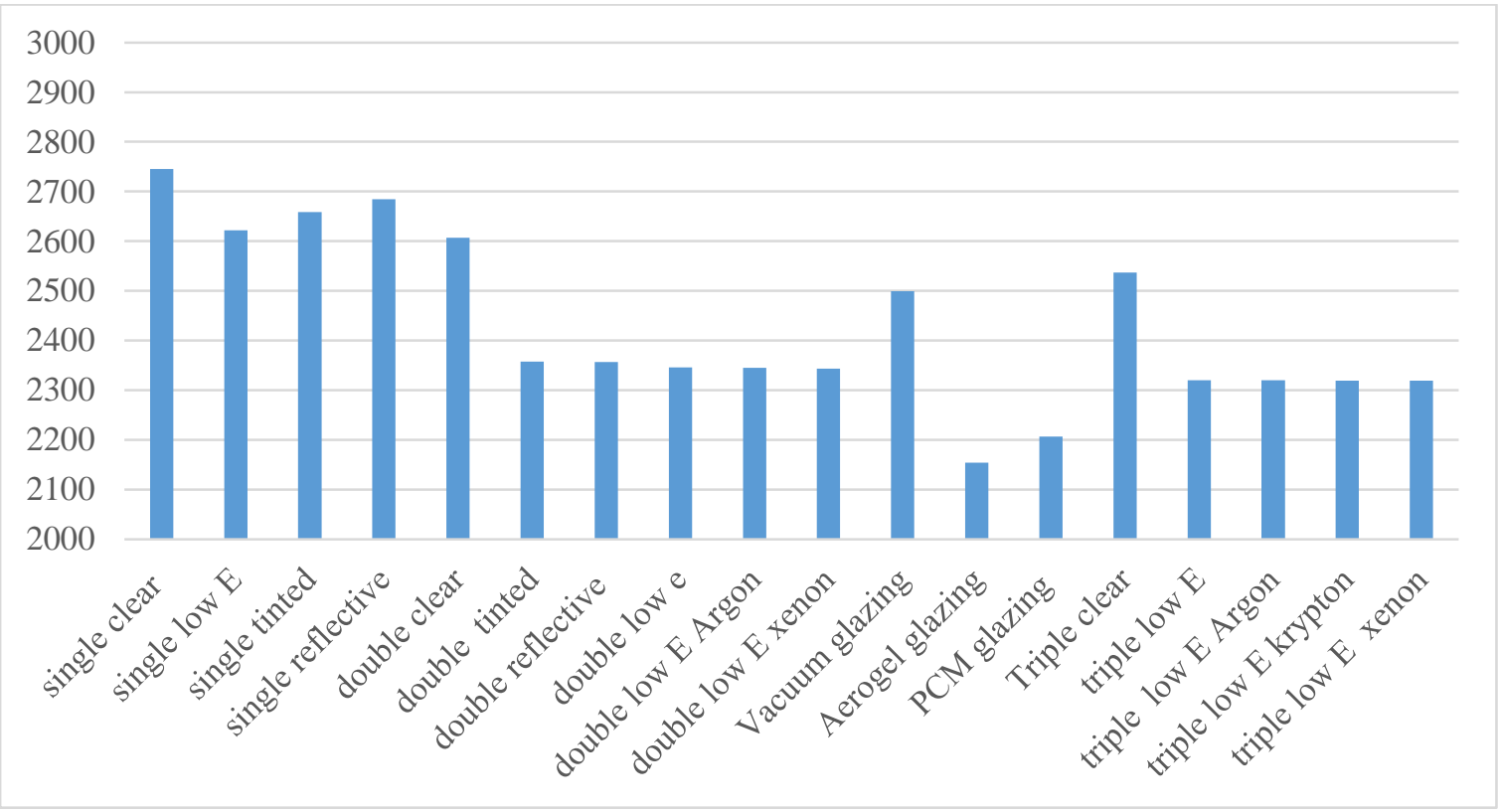

Figure 7 : Total loads in KWH by each glazing type

From the previous figure we can deduce that:

- The single glazing is the worst option to be chosen among all glazing types while the aerogel is the best option. 
- The single low-E glazing can be the best type among single glazing types followed by the tinted glazing.

- The aerogel glazing is the best option between all double-glazing types followed by the PCM glazing. The double gas filled glazing with xenon is the best among all gases but the difference between double gas filled in not noticeable.

- The triple low-E xenon is the best among triple glazing types and the difference between the different gases in not remarkable.

- Comparing between clear glazing, the difference between the single, double and triple is big but when comparing between double and triple clear, there is a difference but not very huge.

\section{Recommendations}

For future investigations considering glazing studies for the enhancement of thermal and lighting performance, it is recommended to merge more of glazing types together. As an example, merging the conventional types with the advanced like the vacuum glazing with tinted glass panes or the low-E glazing with the vacuum or the PCM glazing. Also it is preferable to investigate the effect the glazing types in each orientation to know if the difference will be remarkable or some orientations don't need IGU.

\section{References}

Aguilar-Santana, J. L., Jarimi, H., Velasco-Carrasco, M., \& Riffat, S. (2019). Review on window-glazing technologies and future prospects. International Journal of LowCarbon Technologies, 15(1), 112-120. https://doi.org/10.1093/ijlct/ctz032

Ali, H., Hayat, N., Farukh, F., Imran, S., Kamran, M. S., \& Ali, H. M. (2017). Key design features of Multi-Vacuum glazing for windows a review. Thermal Science, 21(6), 2673-2687. https://doi.org/10.2298/TSCI151006051A

Aruteb, D., \& Griffith, B. T. (1991). Gas Filled Panels : A Thermally Improved Building Insulation. Thermal Performance of the Exterior Envelopes of Buildings $V$ Conference Proceedings, 1990(Griffith).

Berardi, U. (2015). The development of a monolithic aerogel glazed window for an energy retrofitting project. Applied Energy, 154, 603-615. https://doi.org/10.1016/j.apenergy.2015.05.059

Bizoňová, S., \& Bagoňa, M. (2019). Gas filling in glass system. International Review of Applied Sciences and Engineering, 10(1), 43-50. https://doi.org/10.1556/1848.2019.0007

Buratti, C., \& Moretti, E. (2012). Experimental performance evaluation of aerogel glazing systems. Applied Energy, 97, 430-437. https://doi.org/10.1016/j.apenergy.2011.12.055

Dowson, M., Harrison, D., Craig, S., \& Gill, Z. (2011). Improving the thermal performance of single-glazed windows using translucent granular aerogel. 
International Journal of Sustainable Engineering, 4(3), 266-280. https://doi.org/10.1080/19397038.2011.558931

Gaoxun, J. (2012). The reasonable ways to reduce the heat losses from windows. 1-37.

Ghoshal, S., \& Neogi, S. (2014). Advance glazing system - Energy efficiency approach for buildings a review. Energy Procedia, 54, 352-358. https://doi.org/10.1016/j.egypro.2014.07.278

Goia, F. (2017). Thermo-physical behaviour and energy performance assessment of PCM glazing system configurations: A numerical analysis. Collection of Frontiers of Architectural Research. https://www.scipedia.com/public/Goia_2012a

Karlsson, J. (2001). Windows: optical performance and energy efficiency. http://uu.divaportal.org/smash/record.jsf?pid=diva2:161001

Lawrence Berkeley Nation Laboratory. (2017). THERM 7 NFRC Simulation Manual. July, $\quad 434 . \quad$ https://windows.lbl.gov/sites/default/files/Downloads/NFRCSim7July2017.pdf

Pérez-Lombard, L., Ortiz, J., \& Pout, C. (2008). A review on buildings energy consumption information. Energy and Buildings, 40(3), 394-398. https://doi.org/10.1016/j.enbuild.2007.03.007

Rathi, P. (2012). Optimization of Energy Efficient Windows in Office Buildings. In Kent State University.

Rezaei, S. D., Shannigrahi, S., \& Ramakrishna, S. (2017). A review of conventional, advanced, and smart glazing technologies and materials for improving indoor environment. Solar Energy Materials and Solar Cells, 159(October), 26-51. https://doi.org/10.1016/j.solmat.2016.08.026

Saint-Gobain. (2018). Solar \& Thermal 1E Thermal Insulation. https://techhub.uk.saintgobain-building-glass.com/sites/default/files/document-files/Solar \%26 Thermal 1E - Thermal Insulation - 19-09-2018.pdf

Schultz, J. M., \& Jensen, K. I. (2008). Evacuated aerogel glazings. Vacuum, 82(7), 723 729. https://doi.org/10.1016/j.vacuum.2007.10.019

Vigna, I., Bianco, L., Goia, F., \& Serra, V. (2018). Phase change materials in transparent building envelopes: A Strengths, Weakness, Opportunities and Threats (SWOT) analysis. Energies, 11(1). https://doi.org/10.3390/en11010111 